\title{
DNA methylation and miRNA-1296 act in concert to mediate spatiotemporal expression of KPNA7 during bovine oocyte and early embryonic development
}

\author{
Lei Wang ${ }^{1}$, Jacqelyn M. Hand', Liyuan Fu', George W. Smith² and Jianbo Yao ${ }^{{ }^{*}}$
}

\begin{abstract}
Background: Epigenetic regulation of oocyte-specific maternal factors is essential for oocyte and early embryonic development. KPNA7 is an oocyte-specific maternal factor, which controls transportation of nuclear proteins important for early embryonic development. To elucidate the epigenetic mechanisms involved in the controlled expression of KPNA7, both DNA methylation associated transcriptional silencing and microRNA (miRNA)-mediated mRNA degradation of KPNA7 were examined.
\end{abstract}

Results: Comparison of DNA methylation profiles at the proximal promoter of KPNA7 gene between oocyte and 6 different somatic tissues identified 3 oocyte-specific differentially methylated CpG sites. Expression of KPNA7 mRNA was reintroduced in bovine kidney-derived CCL2 cells after treatment with the methylation inhibitor, 5-aza-2'deoxycytidine (5-Aza-CdR). Analysis of the promoter region of KPNA7 gene in CCL2 cells treated with 5-Aza-CdR showed a lighter methylation rate in all the CpG sites. Bioinformatic analysis predicted 4 miRNA-1296 binding sites in the coding region of KPNA7 mRNA. Ectopic co-expression of miRNA-1296 and KPNA7 in HEK293 cells led to reduced expression of KPNA7 protein. Quantitative real time PCR (RT-qPCR) analysis revealed that miRNA-1296 is expressed in oocytes and early stage embryos, and the expression reaches a peak level in 8-cell stage embryos, coincident with the time of embryonic genome activation and the start of declining of KPNA7 expression.

Conclusions: These results suggest that DNA methylation may account for oocyte-specific expression of KPNA7, and miRNA-1296 targeting the coding region of KPNA7 is a potential mechanism for KPNA7 transcript degradation during the maternal-to-zygotic transition.

Keywords: DNA methylation, miRNA, Oocyte, Early embryonic development, Maternal, Cattle

\section{Background}

Successful germ cell development and differentiation during oogenesis and early embryogenesis is accomplished through the help of nuclear proteins such as transcription factors and chromatin-remodeling factors that act in the nucleus [1]. A family of nuclear transporters called karyopherins are the major players in the translocation of nuclear proteins through an active, energy-dependent nuclear import system. To date, seven

\footnotetext{
* Correspondence: jianbo.yao@mail.wvu.edu

${ }^{1}$ Laboratory of Animal Biotechnology and Genomics, Division of Animal and Nutritional Sciences, West Virginia University, Morgantown, WV 26506, USA Full list of author information is available at the end of the article
}

members of karyopherin alpha (KPNA) have been identified in mammals; only KPNA7 is strictly expressed in oocytes and early embryos [2-4]. In mice, KPNA7 knockout lead to fetal lethality, sex imbalance and abnormalities of epigenetic modifications (e.g. downregulation of histone H3K27me3) [3]. In livestock species, such as cattle and pigs, knockdown of KPNA7 significantly reduces blastocyst rate through inducing arrested embryonic development $[2,4]$. In cattle, the expression of KPNA7 is high in germinal vesicle (GV) oocytes through 8-cell stage embryos but drops to barely detectable levels in morula and blastocyst stage embryos [2]. The sudden drop of mRNA levels during the 8-16

(c) The Author(s). 2019 Open Access This article is distributed under the terms of the Creative Commons Attribution 4.0 International License (http://creativecommons.org/licenses/by/4.0/), which permits unrestricted use, distribution, and reproduction in any medium, provided you give appropriate credit to the original author(s) and the source, provide a link to the Creative Commons license, and indicate if changes were made. The Creative Commons Public Domain Dedication waiver (http://creativecommons.org/publicdomain/zero/1.0/) applies to the data made available in this article, unless otherwise stated. 
cell stages is coincident with the time of maternal-tozygotic transition (MZT) in cattle. To date, little is known about the mechanistic control of tissue- and stage-specific expression of KPNA7.

DNA methylation at the 5-position of cytosine $(5 \mathrm{mC})$ largely occurs at $\mathrm{CpG}$ dinucleotides and is required for normal gametogenesis and embryogenesis in mammals [5]. In the early stages of oogenesis, the genome of embryonic germ cells is dynamically reprogrammed during cell differentiation and the differentially methylated regions begin to maintain the monoallelic expression of imprinted genes [6-8]. Genes of developmental importance, such as germ cell-specific factors Nanog, Dazl, Pouff1 and Sry, which control primordial germ cell development, are all regulated through DNA methylation-mediated mechanisms [9-11]. Tissuespecific and differentially methylated regions are common in the mammalian genome and correspond to different cell types in an organism [12]. Since DNA methylation profile is tissue-specific, it is reasonable to believe that DNA methylation, particularly, methylation in the CpG sites located in the proximal promoter surrounding the transcription start site (TSS), plays a role in controlling the expression of oocyte-specific maternal factors.

Maternal effect genes are the major driving force to facilitate oocyte maturation, fertilization and embryonic genome activation [13]. However, after MZT, almost $90 \%$ of the maternal transcripts are degraded and the clearance of maternal transcripts is proved to be essential for normal embryonic development [14]. For example, in Xenopus laevis, abundance of the oocytespecific maternal transcript $c$-mos is reduced quickly after fertilization, and introducing c-mos protein into 2cell stage embryo led to development block [15]. This phenomenon was observed in the mouse and other species, which indicates that maternal transcript degradation is required for normal embryonic development [16]. Multiple negative regulatory mechanisms including mRNA deadenylation, interaction with RNA-binding proteins and miRNA-mediated degradation are involved in post-transcriptional degradation of maternal transcripts [17]. miRNAs such as miRNA-430 in zebrafish and miRNA-427 in Xenopus were shown to be present prior to embryonic genome activation and further studies revealed more evidence to support the role of these miRNAs in degradation of hundreds of maternal transcripts [18-20]. In cattle, a number of oocytespecific maternal transcripts (e.g. NPM2, NOBOX and FIGLA) were shown to be targeted by miRNAs for their degradation [21-23].

In the present study, we identified oocyte-specific differentially methylated CpG sites in the promoter region of bovine KPNA7 gene and demonstrated that KPNA7
mRNA is potentially targeted by miRNA-1296 for degradation. The results suggest distinctive controlling mechanisms for tissue- and stage-specific expression of bovine KPNA7 gene during oocyte and early embryonic development.

\section{Results \\ KPNA7 promoter is differentially methylated in bovine oocyte and somatic tissues}

It has been generally believed that DNA hypermethylation at the proximal promoter can repress gene transcription by interfering with transcription initiation [24]. Therefore, differentially methylated promoter region of KPNA7 gene may contribute to its oocytespecific expression. Analysis of the genomic DNA sequence around the transcription start site (TSS) of KPNA7 gene using an online algorithm (Methprimer) revealed multiple $\mathrm{CpG}$ sites including a $\mathrm{CpG}$ island containing 8 CpG sites (-221 to - 114) located upstream of the TSS (Additional file 1. Figure S1). Using bisulfite conversion and subsequent DNA sequencing, the methylation status of 11 consecutive CpG sites including 8 within the $\mathrm{CpG}$ island and 3 located right before the TSS at the CPG island shore region were characterized. Three hypomethylated CpG sites $(-149$, -63 and -54) with high demethylation rates $(60-70 \%)$ were identified in the GV oocyte in comparison to 6 different somatic tissues including heart, lung, muscle, brain, intestine and spleen (Fig. 1). The hypomethylation pattern observed in the 3 sites was found to exist only in the GV oocyte with no more than $20 \%$ demethylation observed in any of the somatic tissues examined, which indicates a tissue-specific methylation pattern of these 3 CpG sites.

\section{Treatment with 5-Aza-CdR reintroduces expression of KPNA7 in CCL-22 cells}

CCL-22 cells are derived from bovine kidney cells, which do not express KPNA7 naturally. 5-Aza-CdR inhibits activity of DNA methyltransferase 1 (DNMT1), an enzyme that maintains the status of DNA methylation. As cells divide, treatment of 5 -Aza-CdR results in global demethylation of the cell genome, and thereby induces the expression of genes silenced by DNA methylation [25]. As shown in Fig. 2a, KPNA7 expression was induced in the 5-Aza-CdR treated cells. Bisulfite sequencing of CCL-22 cells from the treatment $(0.5 \mu \mathrm{M})$ and the control groups showed demethylation of the KPNA7 proximal promoter in the treatment group, whereas in the control group, hypermethylation was observed (Fig. 2b), which agrees with the RT-PCR results showing no expression of KPNA7 mRNA in the control group. Three oocyte-specific hypomethylated sites $(-149,-63$, and -54 ) are all methylated in the control group, and in 


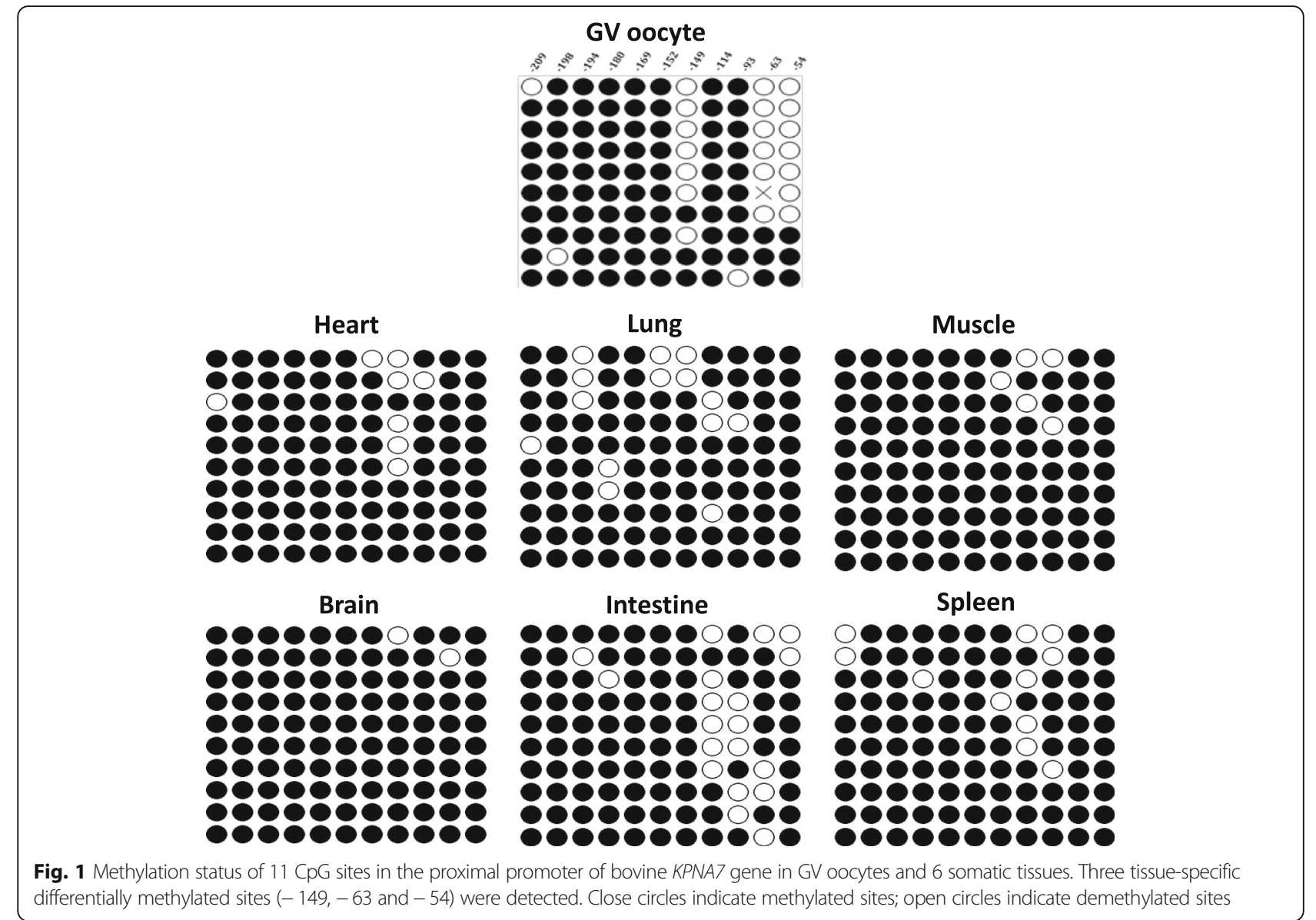

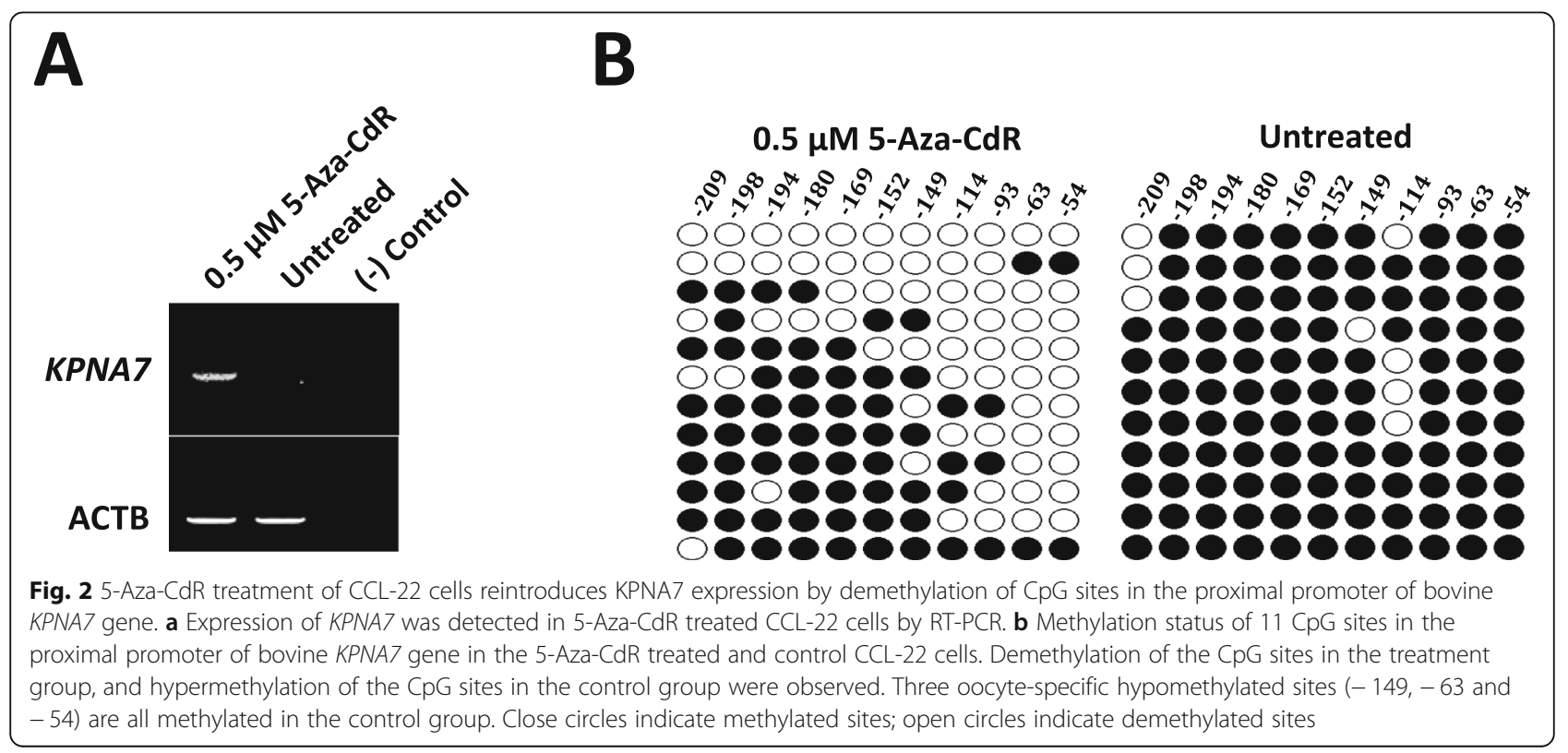


the treatment group they underwent partial demethylation showing resemblance to the methylation status found in oocytes. These results indicate that DNA methylation in the proximal promoter of KPNA7 gene is critical for its tissue-specific expression, and the 3 oocyte-specific hypomethylated sites may play a primary role in controlling KPNA7 tissue-specificity.

\section{Promoter demethylation does not activate KPNA7} expression after embryonic genome activation

As a maternal effect gene, KPNA7 is only expressed in oocyte and early embryos in which the expression level is high until it rapidly decreases after MZT $(\sim 16$-cell stage) and does not increase again until the formation of primordial germ cells in late pregnancy [2]. Therefore, 16-cell and blastocyst stage embryos were used to test if silencing of KPNA7 expression was due to DNA methylation in the promoter region. Bisulfite sequencing and subsequent analysis showed that in 16-cell stage embryos, the KPNA7 proximal promoter is heavily hypomethylated (Fig. 3). At the further developmental stage, when the embryonic genome is completely activated, the KPNA7 proximal promoter is still extremely hypomethylated. This pattern shows that DNA methylation of the CpG sites at the proximal promoter does not control KPNA7 expression in embryos after MZT, and thus silencing of KPNA7 expression in embryos after the 16cell stage is likely due to other mechanisms.

\section{miRNA-1296 is potentially involved in translational} silencing of bovine KPNA7

To identify miRNAs that may target KPNA7, the KPNA7 cDNA sequence (GenBank accession No. FJ754641) was uploaded to the online algorithm "Microinspector" (http://bioinfo.uni-plovdiv.bg/microinspector/) to predict miRNA binding sites. Four miRNA-1296 recognition elements in the coding region of KPNA7 mRNA were predicted (Fig. 4). Co-transfection of expression constructs harboring miRNA-1296 and KPNA7 showed a reduction of KPNA7 protein expression in HEK293 cells compared to the cells transfected with KPNA7 expression construct alone (Fig. 5a). This experiment was repeated three times and quantitative analysis of western blot data showed a significant reduction of KPNA7 protein in the co-transfection group (Fig. 5b). The results suggest that miRNA-1296 may play a role in the regulation of bovine KPNA7 expression at the posttranscriptional level. RT-qPCR analysis showed that miRNA-1296 expression reaches its peak level in the 8-cell stage embryo, which is coincident with the start of declining of KPNA7 expression (Fig. 6). The data supports our hypothesis that miRNA-1296 acts as a functional physiological regulator for KPNA7 expression during early embryogenesis.

\section{Discussion}

Tissue-specific deferential methylation has become an important aspect in epigenetic-related gene expression studies [26, 27]. Comparisons between oocyte and sperm, developmental germ cell stages, and different embryonic stages showed stage- or germ cell- specific differentially methylated regions $[28,29]$. In this study, we demonstrated that methylation of 3 CpG sites $(-149$, -63 and -54) in the promoter region controls tissuespecific expression of bovine KPNA7 gene. Two of the differentially methylated sites are located in the $\mathrm{CpG}$ island shore region $(-63$ and -54$)$. The role of $\mathrm{CpG}$ island shore regions in controlling gene expression has been recently demonstrated [30,31].

Control of gene expression by specific CpG sites was observed in a previous study in prostate cancer cells [32]. When treated with a minimal concentration of 5-

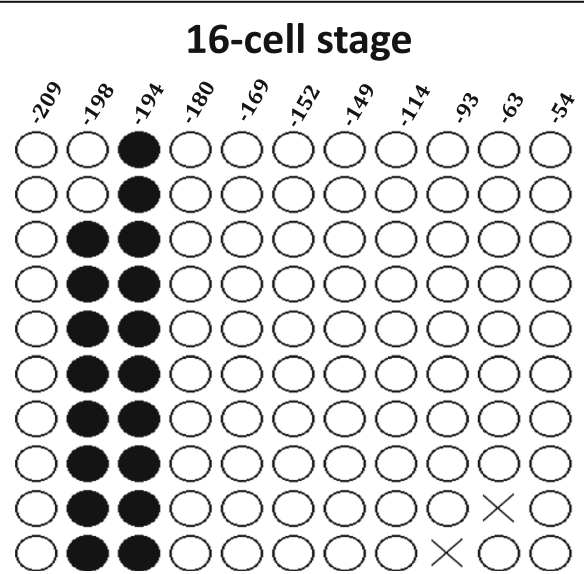

Blastocyst stage
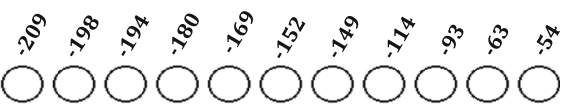

00000000000

00000000000
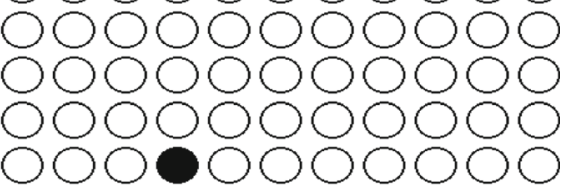

00000000000

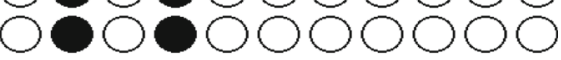

$00000000 \times 00$

Fig. 3 Methylation status of $11 \mathrm{CpG}$ sites in the proximal promoter of bovine KPNA7 gene in 16-cell and blastocyst stage embryos. Hypomethylation of the CpG sites were observed in both stage embryos. Close circles indicate methylated sites; open circles indicate demethylated sites 

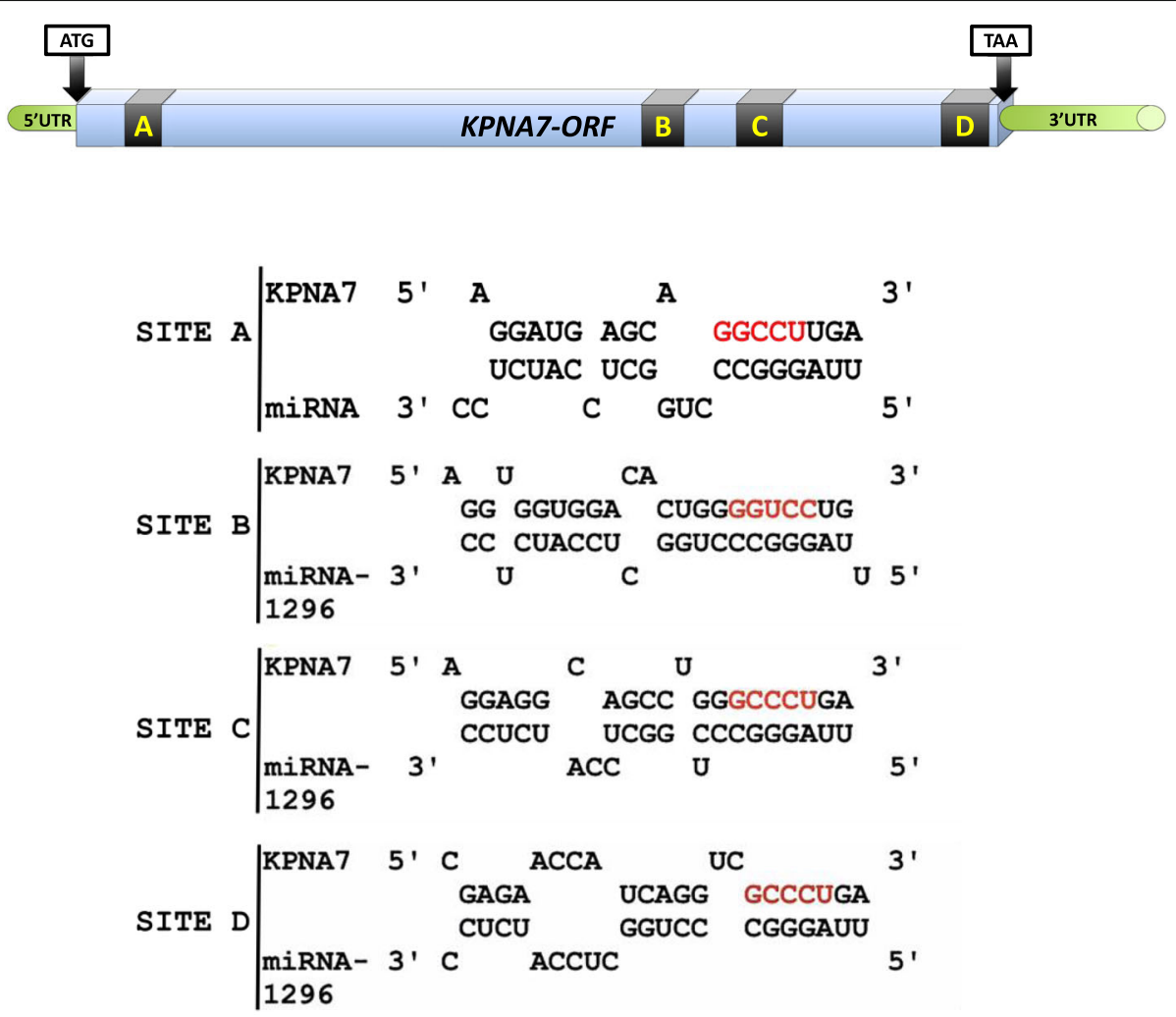

Fig. 4 Prediction of miRNA-1296 binding sites in the coding region of bovine KPNA7 mRNA. Four putative miRNA-1296 binding sites (A, B, C and D) were predicted using the online software Microinspector (http://bioinfo.uni-plovdiv.bg/microinspector/)

Aza-CdR, one CpG site was hypersensitive to the challenge and methylation of this single site led to silencing of PMP24 gene. In the present study, we observed that demethylation of CpG sites tends to spread from the TSS towards the upstream positions. Two sites $(-63$ and -54) closest to the TSS had the highest demethylation level than did the sites located upstream, suggesting a primary role of these 2 sites in controlling the expression of KPNA7 gene.

After fertilization, the paternal genome undergoes spontaneous global demethylation before first cleavage but the maternal genome retains its methylation status until the first cleavage event in which demethylation occurs passively with each cell division [33]. In cattle,

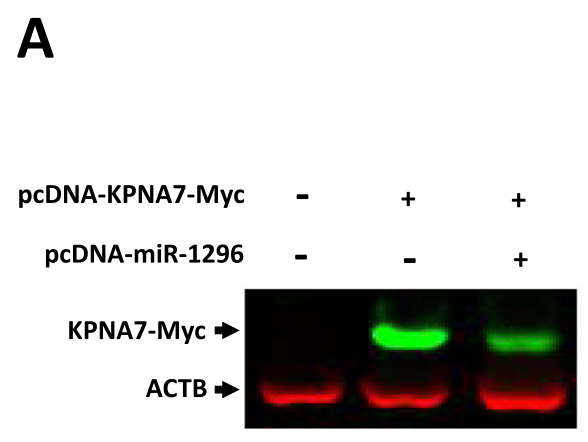

\section{B}

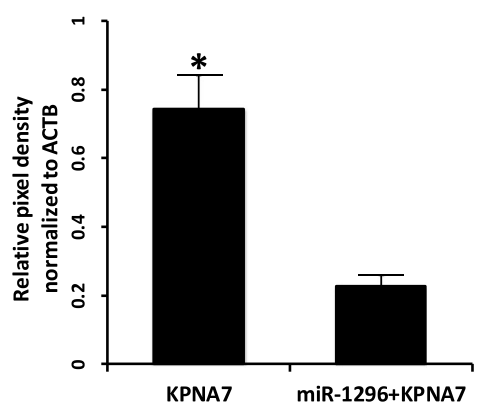

Fig. 5 miRNA-1296 suppresses the expression of KPNA7 protein in HEK293 cells. a A representative western blot showing reduction of KPNA7 protein in HEK293 cells expressing miRNA-1296. ACTB was used as a loading control. The experiment was repeated three times. b ImageJ software was used to quantify the protein bands. Abundance of KPNA7 protein was normalized relative to abundance of ACTB protein. Data are expressed as mean relative pixel density $(n=3$, mean \pm SEM). Asterisk indicates statistical difference $(P<0.05)$ 


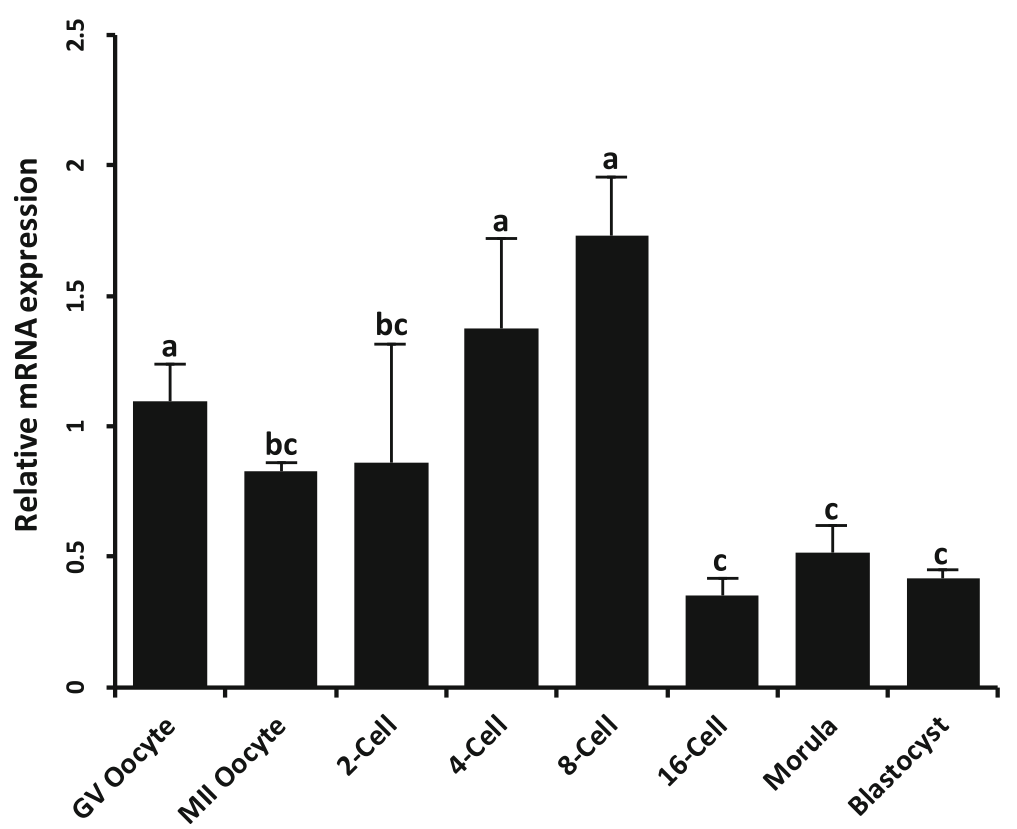

Fig. 6 Relative abundance of miR-1296 mRNA in bovine oocytes and in vitro produced bovine early embryos ( $n=4$ pools of five oocytes/ embryos each). Quantity of miRNA was normalized relative to abundance of miRNA-125b. Different letters indicate statistical difference $(P<0.05)$

the embryonic genome is mostly activated by the 16 -cell stage and is completely activated in the blastocyst stage embryo. The methylation status of the $5^{\prime}$ terminal region near the TSS of developmentally important genes has been surveyed and all the genes, including Oct4, Sox2, Nanog, Rex1 and Fgf4, experienced demethylation after fertilization and the expression of these genes were not accompanied by the demethylation of their promoter regions [34]. Therefore, the dynamic methylation changes in early embryonic development, especially during MZT, might not contribute to activation of gene transcription. In this case, the reduction of KPNA7 mRNA level is explained by inactivation of transcriptional activity, however, on the other hand, rapid mRNA degradation might also be a reason for diminishment of the KPNA7 transcript.

With 4 predicted miRNA-1296 binding sites in the coding region of KPNA7 mRNA, the functional role of miRNA-1296 in regulation of KPNA7 expression was investigated. Our co-transfection experiments indicated that miRNA-1296 may play a role in down-regulating the expression of KPNA7 protein. However, this finding is limited as we did not show specific binding of miRNA-1296 to the predicted binding sites on KPNA7 mRNA. Further experiments using reporter constructs with mutated miRNA-1296 binding sites are needed to test whether the effect of miRNA-1296 on KPNA expression is direct or indirect.

The classic miRNA-mediated post-transcriptional regulation of mRNAs has been believed to be confined to the 3'UTR region of the transcripts [35]. However, new studies have demonstrated the existence of many naturally occurring alternative binding regions of miRNA in mammalian cells [36, 37]. During embryogenesis, miR-134, miR-296 and miR-470 target the coding regions of transcription factors Nanog, Oct 4 and Sox 2 in various combinations, leading to transcriptional and morphological changes in mouse embryonic stem cells [36]. In bovine species, Nanog, Oct4 and Sox 2 are all oocyte-specific maternal factors that govern early embryonic development by regulating the pluripotency of blastomeres [38, 39]. Thus, miRNA targeting the coding regions of developmentally important factors might be a characteristic feature in post-transcriptional regulation of maternal effect factors.

Targets of miRNA-1296 have been studied and shown to be highly involved in essential DNA replication [40]. miRNA-1296 targets MCM2 mRNA in prostate cancer cells and over expression of miRNA-1296 results in a significant decrease in MCM2 mRNA, protein, and S-phase of the cell cycle. MCM2 is an essential DNA replication factor that is highly expressed in cancer cells as well as in the oocyte and is highly involved in resumption of meiosis in mammalian oocytes [41]. The potential involvement of miRNA-1296 in regulating the expression of KPNA7 supports a new role of this miRNA in the control of oocyte and early embryonic development.

Studies in human cancers have shown that miRNAs and DNA methylation can mutually regulate each other 
[42]. For example, the miRNA-29 family regulates DNA methylation by targeting DNA methyltransferases (DNMT3a and DNMT3b) in lung cancer tissues [43], and the expression of the miRNA-34 family members (miRNA-34b and miRNA-34c) is silenced by hypermethylation of the promoters of the miRNA genes in gastric cancer cells [44]. It is not clear how the expression of bovine miRNA-1296 is regulated during embryogenesis but DNA methylation of the miRNA gene promoter could play a role in controlling its expression. There is currently no evidence showing the involvement of miRNA-1296 in modulating DNA methyltransferases, thus affecting DNA methylation.

\section{Conclusions}

In this study, we found that the oocyte restricted expression of bovine KPNA7 is regulated by DNA methylation at the proximal promoter and demethylation of $3 \mathrm{CpG}$ sites is closely related to tissue-specific expression of this gene. We also provided evidence showing that miRNA1296 is potentially involved in translational silencing of bovine KPNA7 through binding sites in the coding region of KPNA7 mRNA. This study combined two aspects of epigenetic regulation of gene expression and discovered distinctive controlling mechanisms for tissueand stage-specific expression of bovine KPNA7 gene.

\section{Methods}

\section{Sample collection}

Bovine tissue samples including heart, lung, muscle, brain, intestine and spleen were collected at a local abattoir. Bovine GV oocytes and early stage embryos were purchased from Bomed, Inc. (Madison, WI). All samples were frozen in liquid nitrogen and stored at $-80^{\circ} \mathrm{C}$ until use.

\section{Plasmid construction}

The open reading frame (ORF) of bovine KPNA7 cDNA was PCR amplified from a KPNA7 expression plasmid [2] and cloned into pcDNA3.1/myc-His vector (Invitrogen, Carlsbad, CA) using a forward primer containing a Kozak sequence and BamHI site and a reverse primer containing a XhoI site (Additional file 2, Table S1). The plasmid designed to express the bovine miRNA-1296 was prepared by PCR amplification of a $291 \mathrm{bp}$ genomic fragment containing the pre-miRNA-1296 followed by cloning into pcDNA3.1 vector using a forward primer containing a BamHI site and a reverse primer containing a PmeI site (Additional file 2, Table S1). Both constructs were sequenced to ensure that no mutations were introduced during PCR amplification.

\section{Bisulfite sequencing}

DNA samples isolated from oocytes/embryos or somatic tissues were treated by bisulfite following the manufacturer's instructions of the EZ DNA Methylation-Direct ${ }^{\text {tm }}$ kit (Zymo Research, Irvine, CA). Primers (Additional file 2, Table S1) were designed using Methprimer online program and were used in a $25-\mu \mathrm{l}$ PCR reaction for the first round of 40 cycles. Cycling conditions were as follows: $95^{\circ} \mathrm{C}$ for $9 \mathrm{~min}$ followed by 40 cycles of $95^{\circ} \mathrm{C}$ for $30 \mathrm{~s}, 54{ }^{\circ} \mathrm{C}$ for $30 \mathrm{~s}, 72^{\circ} \mathrm{C}$ for $30 \mathrm{~s}$ and a final extension of 5 min at $72{ }^{\circ} \mathrm{C}$. Nested PCR of 35 cycles was performed using the PCR product as a template in a higher annealing temperature at $58^{\circ} \mathrm{C}$ and a shorter denaturation time of $5 \mathrm{~min}$ at $95^{\circ} \mathrm{C}$. The DNA regions of CpG sites were amplified, and three independent PCR reactions were performed. The PCR products were purified, pooled together and cloned into pGEM-T Easy vector (Promega). After verification, 10 clones for each DNA sample were sequenced, and the sequences were analyzed using the online tool QUMA (http://quma.cdb.riken.jp/).

\section{Cell culture}

HEK293 cells were cultured in DMEM (Invitrogen, Carlsbad, CA) containing 10\% FBS. For transient transfection, Xtremegene 9 (Roche Applied Science, Indianapolis, IN) was used according to manufacturer's instructions. Following transfection, cells were incubated for $24 \mathrm{~h}$ before harvest for western blot analysis. CCL22 cells were cultured in DMEM containing 10\% HS. 5Aza-CdR was added to the culture medium with a final concentration of $0.5 \mu \mathrm{M}$ in 6-well plates (Corning Inc., Corning, NY) seeded with cells $24 \mathrm{~h}$ before the treatment. Treatment continued for 3 days with fresh 5 -Aza-CdR changed every $24 \mathrm{~h}$. After 3 days, cells were harvested and stored at $-80^{\circ} \mathrm{C}$ until use.

\section{Western blot analysis}

Electrophoresis and transfer were performed according to a previous study with minor modifications [45]. HEK293 cell were harvested with Pierce IP Lysis Buffer (Thermo Fisher Scientific, Waltham, MA), and $10 \mu \mathrm{l}$ of cell lysate were mixed with an equal volume of Laemmli sample buffer (Bio-Rad Laboratories, Hercules, CA). Protein samples $(15 \mu \mathrm{g} / \mathrm{each})$ were separated on a $4-20 \%$ gradient ready gel (Bio-Rad) and transferred onto a Immobilon-FL PVDF membrane (Millipore, Billerica, MA). Following transfer and blocking in $5 \%$ nonfat dry milk in PBS containing 0.1\% Tween-20 (PBST) for one hour, the membrane was incubated in anti-Myc antibody (Sigma-Aldrich, St. Louis, MO) diluted 1:1000 and antiACTB antibody (GenScript, Piscataway, NJ) diluted 1: 1000 in blocking buffer overnight at $4{ }^{\circ} \mathrm{C}$. After 3 washes, two secondary antibodies IRDye $800 \mathrm{CW}$ goat anti-rabbit and IRDye 680LT goat anti-mouse (Li-COR, Lincoln, 
$\mathrm{NE})$ were added to the blocking buffer and incubated for $20 \mathrm{~min}$. Detection of protein was performed following the instructions of the Odyssey system (Li-COR, Lincoln, $\mathrm{NE}$ ). ImageJ software was used to quantify the protein bands. Abundance of KPNA7 protein was normalized relative to the abundance of $\mathrm{ACTB}$ protein.

\section{Quantitative real-time PCR}

cDNA from oocyte and embryo samples $(n=3$ pools of five each) was prepared by lysing the samples in $1 \times$ miScript RT buffer containing $0.5 \%$ NP- 40 at $95^{\circ} \mathrm{C}$ for 5 min followed by addition of miScript reverse transcriptase mix (Qiagen, Valencia, CA) and incubation at $37^{\circ} \mathrm{C}$ for $60 \mathrm{~min}$. The cDNA was then used for determination of relative amount of miR-1296 by RT-qPCR using the miRNA-1296 specific primer and the miScript universal primer (Qiagen, Valencia, CA). Bovine miRNA-125b was used as an endogenous control as this miRNA is expressed consistently in preimplantation embryos [46]. RT-qPCR analysis was performed on the Bio-Rad CFX96 system. The $\mathrm{iQ}^{\mathrm{m}}$ SYBR Green Supermix (Bio-Rad, Hercules, CA) was used in $20 \mu \mathrm{l}$ reaction volumes containing $100 \mathrm{nM}$ of each primer and $5 \mu \mathrm{l}$ of diluted cDNA. Cycling parameters were $95^{\circ} \mathrm{C}$ for $15 \mathrm{~min}$, and then 40 cycles of $95^{\circ} \mathrm{C}$ for $15 \mathrm{~s}, 55^{\circ} \mathrm{C}$ for $30 \mathrm{~s}$ and $70^{\circ} \mathrm{C}$ for $30 \mathrm{~s}$. Standard curves for the target and control miRNA were constructed using 10-fold serial dilution of a pooled cDNA sample.

\section{Supplementary information}

Supplementary information accompanies this paper at https://doi.org/10. 1186/s12861-019-0204-X.

Additional file 1: Figure S1. Identification of $\mathrm{CpG}$ sites in the proximal promoter of bovine KPNA7 gene. Analysis of DNA sequence around the transcription start site (TSS) of bovine KPNA7 gene using Methprimer (http://www.urogene.org/cgi-bin/methprimer2/MethPrimer.cgi) revealed multiple CpG sites including a CpG island containing 8 CpG sites ( -221 to - 114) located upstream of the TSS. (PPTX $69 \mathrm{~kb}$ )

Additional file 2: Table S1. List of primers used in this study. (XLSX 9 $\mathrm{kb})$

\section{Abbreviations}

5-Aza-CdR: 5-aza-2'-deoxycytidine; 5mC: 5-position of cytosine; DNMT1: DNA methyltransferase 1; GV: germinal vesicle; KPNA: karyopherin alpha; miRNA: microRNA; MZT: maternal-to-zygotic transition; RT-qPCR: quantitative real time PCR; TSS: transcription start site

\section{Acknowledgements}

Not applicable.

\section{Authors' contributions}

LW performed most of the experiments including methylation analysis, preparation of constructs and cell transfection. LW also drafted the manuscript. JMH and LF helped in sample collection and gene expression analysis. GWS and JY designed the study and supervised the experimental work. All authors read and approved the final manuscript.

\section{Funding}

This work was supported by Agriculture and Food Research Initiative Competitive Grant no. 2016-67015-24919 from the USDA National Institute of Food and Agriculture and funds from the West Virginia Agricultural and Forestry Experiment Station (Hatch project No. 427). The funding agencies had no input on the design of the study, collection, analysis and interpretation of the data, and writing of the manuscript.

\section{Availability of data and materials}

The datasets used and/or analyzed during the current study are available from the corresponding author on reasonable request.

Ethics approval and consent to participate

Not applicable.

\section{Consent for publication}

Not applicable.

\section{Competing interests}

The authors declare that they have no competing interests.

\section{Author details}

${ }^{1}$ Laboratory of Animal Biotechnology and Genomics, Division of Animal and Nutritional Sciences, West Virginia University, Morgantown, WV 26506, USA.

${ }^{2}$ Laboratory of Mammalian Reproductive Biology and Genomics,

Departments of Animal Science and Physiology, Michigan State University, East Lansing, MI 48824, USA.

Received: 22 May 2019 Accepted: 27 October 2019

Published online: 02 December 2019

\section{References}

1. Itman C, Miyamoto Y, Young J, Jans D, Loveland K: Nucleocytoplasmic transport as a driver of mammalian gametogenesis. In: Seminars in cell and developmental biology: 2009. Elsevier: 607-619.

2. Tejomurtula J, Lee K, Tripurani SK, Smith GW, Yao J. Role of Importin Alpha8, a new member of the Importin alpha family of nuclear transport proteins, in early embryonic development in cattle. Biol Reprod. 2009; 81(000268277300012):333-42.

3. Hu J, Wang F, Yuan Y, Zhu X, Wang Y, Zhang Y, Kou Z, Wang S, Gao S. Novel importin-alpha family member Kpna7 is required for normal fertility and fecundity in the mouse. J Biol Chem. 2010;285(20699224):33113-22.

4. Wang X, Park KE, Koser S, Liu S, Magnani L, Cabot RA. KPNA7, an oocyte-and embryo-specific karyopherin a subtype, is required for porcine embryo development. Fertility and Development: Reproduction; 2011.

5. Messerschmidt DM: Should I stay or should I go: Protection and maintenance of DNA methylation at imprinted genes. In: Epigenetics. vol. 7; 2012.

6. Panning $B$, Jaenisch R. DNA hypomethylation can activate Xist expression and silence X-linked genes. Genes Dev. 1996;10(16):1991-2002.

7. Kass SU, Landsberger N, Wolffe AP. DNA methylation directs a timedependent repression of transcription initiation. Curr Biol. 1997;7(3):157-65.

8. Maeda C, Sato S, Hattori N, Tanaka S, Yagi S, Shiota K. DNA hypomethylation circuit of the mouse oocyte-specific histone $\mathrm{H} 1$ foo gene in female germ cell lineage. Biol Reprod. 2008;78(18184919):816-21.

9. Nishino K, Hattori N, Tanaka S, Shiota K. DNA methylation-mediated control of Sry gene expression in mouse gonadal development. J Biol Chem. 2004; 279(21):22306-13.

10. Hattori N, Nishino K, Ko Y, Hattori N, Ohgane J, Tanaka S, Shiota K. Epigenetic control of mouse Oct-4 gene expression in embryonic stem cells and trophoblast stem cells. J Biol Chem. 2004;279(17):17063-9.

11. Maatouk DM, Kellam LD, Mann MRW, Lei H, Li E, Bartolomei MS, Resnick JL. DNA methylation is a primary mechanism for silencing postmigratory primordial germ cell genes in both germ cell and somatic cell lineages. Development. 2006;133(17):3411-8.

12. Shiota K. DNA methylation profiles of $\mathrm{CpG}$ islands for cellular differentiation and development in mammals. Cytogenetic and genome research. 2004; 105(2-4):325-34.

13. Li L, Zheng P, Dean J. Maternal control of early mouse development. Development. 2010;137(6):859-70. 
14. Paynton BV, Rempel R, Bachvarova R. Changes in state of adenylation and time course of degradation of maternal mRNAs during oocyte maturation and early embryonic development in the mouse. Dev Biol. 1988;129(2):304-14.

15. Sagata N, Watanabe N, Woude GFV, Ikawa Y: The c-Mos proto-oncogene product is a cytostatic factor responsible for meiotic arrest in vertebrate eggs. 1989.

16. Alizadeh Z, Kageyama S, Aoki F. Degradation of maternal mRNA in mouse embryos: selective degradation of specific mRNAs after fertilization. Mol Reprod Dev. 2005;72(16094646):281-90.

17. Bettegowda A, Smith GW. Mechanisms of maternal mRNA regulation: implications for mammalian early embryonic development. Frontiers in bioscience : a journal and virtual library. 2007;12:3713-26.

18. Bazzini AA, Lee MT, Giraldez AJ: Ribosome profiling shows that miR-430 reduces translation before causing mRNA decay in zebrafish. Science (New York, NY) 2012, 336(22422859):233-237.

19. Lund E, Liu M, Hartley RS, Sheets MD, Dahlberg JE: Deadenylation of maternal mRNAs mediated by miR-427 in Xenopus laevis embryos. RNA (New York, NY) 2009, 15(19854872):2351-2363.

20. Giraldez AJ, Mishima Y, Rihel J, Grocock RJ, Van Dongen S, Inoue K, Enright AJ, Schier AF. Zebrafish MiR-430 promotes deadenylation and clearance of maternal mRNAs. Science (New York, NY). 2006:312(16484454):75-9.

21. Tripurani SK, Lee K, Wee G, Smith GW, Yao J. MicroRNA-196a regulates bovine newborn ovary homeobox gene (NOBOX) expression during early embryogenesis. BMC Dev Biol. 2011;11(21548929):25.

22. Tripurani SK, Wee G, Lee K, Smith GW, Wang L. Jianboyao: MicroRNA-212 post-transcriptionally regulates oocyte-specific basic-helix-loop-helix transcription factor, factor in the germline alpha (FIGLA), during bovine early embryogenesis. PLoS One. 2013;8(24086699):e76114.

23. Lingenfelter BM, Tripurani SK, Tejomurtula J, Smith GW, Yao J. Molecular cloning and expression of bovine nucleoplasmin 2 (NPM2): a maternal effect gene regulated by miR-181a. Reprod Biol Endocrinol. 2011;9:40.

24. Borgel J, Guibert S, Li Y, Chiba H, Schübeler D, Sasaki H, Forné T, Weber M. Targets and dynamics of promoter DNA methylation during early mouse development. Nat Genet. 2010;42(21057502):1093-100.

25. Jones PA. Effects of 5-azacytidine and its 2'-deoxyderivative on cell differentiation and DNA methylation. Pharmacol Ther. 1985;28(1):17-27.

26. Song F, Mahmood S, Ghosh S, Liang P, Smiraglia DJ, Nagase H, Held WA. Tissue specific differentially methylated regions (TDMR): changes in DNA methylation during development. Genomics. 2009;93(18952162):130-9.

27. Canastar A, Logel J, Graw S, Finlay-Schultz J, Osborne C, Palionyte M, Drebing C, Plehaty M, Wilson L, Eyeson R, et al. Promoter methylation and tissue-specific transcription of the a7 nicotinic receptor gene, CHRNA7. J Mol Neurosci. 2012;47(2):389-400.

28. Kobayashi H, Sakurai T, Imai M, Takahashi N, Fukuda A, Yayoi O, Sato S, Nakabayashi K, Hata K, Sotomaru Y. Contribution of intragenic DNA methylation in mouse gametic DNA methylomes to establish oocytespecific heritable marks. PLoS Genet. 2012:8(1):e1002440.

29. Smallwood SA, Tomizawa S, Krueger F, Ruf N, Carli N, Segonds-Pichon A, Sato S, Hata K, Andrews SR, Kelsey G. Dynamic CpG island methylation landscape in oocytes and preimplantation embryos. Nat Publ Group. 2011;43(8):811-4.

30. Rao X, Evans J, Chae H, Pilrose J, Kim S, Yan P, Huang R, Lai H, Lin H, Liu Y. $\mathrm{CpG}$ island shore methylation regulates caveolin-1 expression in breast cancer. Oncogene. 2013;32(38):4519-28.

31. Irizarry RA, Ladd-Acosta C, Wen B, Wu Z, Montano C, Onyango P, Cui H, Gabo K, Rongione M, Webster M. Genome-wide methylation analysis of human colon cancer reveals similar hypo-and hypermethylation at conserved tissue-specific CpG island shores. Nat Genet. 2009;41(2):178.

32. Zhang $X$, Wu M, Xiao H, Lee $M$, Levin L, Leung $Y$, Ho S. Methylation of a single intronic CpG mediates expression silencing of the PMP24 gene in prostate cancer. Prostate. 2010;70(20054818):765-76.

33. Santos F, Hendrich B, Reik W, Dean W. Dynamic reprogramming of DNA methylation in the early mouse embryo. Dev Biol. 2002;241(11784103):172-82.

34. Lan J, Hua S, Zhang H, Song Y, Liu J, Zhang Y. Methylation patterns in 5 'terminal regions of pluripotency-related genes in bovine in vitro fertilized and cloned embryos. Journal of Genetics and Genomics. 2010; 37(10301776905780968566related:drxIwIND944J):297-304.

35. Bartel DP. MicroRNAs: genomics, biogenesis, mechanism, and function. Cell. 2004;116(14744438):281-97.

36. Tay Y, Zhang J, Thomson AM, Lim B, Rigoutsos I. MicroRNAs to Nanog, Oct4 and Sox2 coding regions modulate embryonic stem cell differentiation. Nature. 2008;455(7216):1124-8.
37. Mandke P, Wyatt N, Fraser J, Bates B, Berberich SJ, Markey MP. MicroRNA34a modulates MDM4 expression via a target site in the open Reading frame. PLoS One. 2012;7(22870278):e42034.

38. Goissis MD, Cibelli JB. Functional characterization of SOX2 in bovine Preimplantation embryos. Biol Reprod. 2014;90(24389873):30.

39. Kurosaka S, Eckardt S, McLaughlin KJ. Pluripotent lineage definition in bovine embryos by Oct4 transcript localization. Biol Reprod. 2004; 71(15229144):1578-82

40. Majid S, Dar AA, Saini S, Chen Y, Shahryari V, Liu J, Zaman MS, Hirata H, Yamamura S, Ueno K, et al. Regulation of minichromosome maintenance gene family by microRNA-1296 and genistein in prostate cancer. Cancer Res. 2010;70(7):2809-18.

41. Swiech L, Kisiel K, Czolowska R, Zientarski M, Borsuk E. Accumulation and dynamics of proteins of the MCM family during mouse oogenesis and the first embryonic cell cycle. Int J Dev Biol. 2007:51(4):283.

42. Wang $S$, Wu W, Claret FX. Mutual regulation of microRNAs and DNA methylation in human cancers. Epigenetics. 2017;12(3):187-97.

43. Fabbri M, Garzon R, Cimmino A, Liu Z, Zanesi N, Callegari E, Liu S, Alder H, Costinean S, Fernandez-Cymering C, et al. MicroRNA-29 family reverts aberrant methylation in lung cancer by targeting DNA methyltransferases 3A and 3B. Proc Natl Acad Sci U S A. 2007;104(40):15805-10.

44. Suzuki H, Yamamoto E, Nojima M, Kai M, Yamano HO, Yoshikawa K, Kimura T, Kudo T, Harada E, Sugai T, et al. Methylation-associated silencing of microRNA-34b/c in gastric cancer and its involvement in an epigenetic field defect. Carcinogenesis. 2010;31(12):2066-73.

45. Wang L, Tripurani SK, Wanna W, Rexroad CE, Yao J. Cloning and characterization of a novel oocyte-specific gene encoding an F-box protein in rainbow trout (Oncorhynchus mykiss). Reprod Biol Endocrinol. 2013;11:86.

46. Byrne MJ, Warner CM. MicroRNA expression in preimplantation mouse embryos from Ped gene positive compared to Ped gene negative mice. J Assist Reprod Genet. 2008;25(5):205-14

\section{Publisher's Note}

Springer Nature remains neutral with regard to jurisdictional claims in published maps and institutional affiliations.

Ready to submit your research? Choose BMC and benefit from:

- fast, convenient online submission

- thorough peer review by experienced researchers in your field

- rapid publication on acceptance

- support for research data, including large and complex data types

- gold Open Access which fosters wider collaboration and increased citations

- maximum visibility for your research: over $100 \mathrm{M}$ website views per year

At BMC, research is always in progress.

Learn more biomedcentral.com/submissions 